Images vol.VIII/no.15-16 Poznań 2011 ISSN 1731-450x

\title{
The challenges of Holocaust instruction and remembrance - Particular and universal aspects in formal and informal interdisciplinary curricula in Israel and abroad
}

Holocaust instruction at schools in Israel is the adolescents' encounter with a phenomenon that is unique in the history of mankind, i.e. the destruction of the Jews during World War II as a coordinated attempt to annihilate the Jewish "race". Adolescents are introduced to curricula that include formal instruction of disciplines such as history and literature, as well as informal instruction involving planning and participating in ceremonies, field trips, study days at Holocaust institutes, the journey to Poland, and volunteer activity on behalf of Holocaust survivors.

Holocaust instruction, despite its complexity, offers the opportunity to encounter the systematic attempt to murder everyone who had Jewish blood flowing in his veins. This is an encounter with the world's first attempted genocide based on racist ideology, rather than religious ideology. Its singularity lies in the all-encompassing intention of its designers and initiators to achieve the complete destruction of all Jews. Despite the long history of persecution of the Jewish people (Graetz, 1954; Hendel, 1950), the act of annihilation by the Nazis was unique in its characteristics - the planning, implementation, scope, execution, and results. All these had never before been seen and therefore had a profound effect on the Jewish people.

The human community as a whole and the Jewish community in particular, have assumed the educational and moral duty to preserve the memory and instill the lessons and values of this inconceivable story, to prevent history from repeating itself. One of the most important means for passing on this memory is by teaching the Holocaust to the younger generation, as this is manifested in curricula in Israel and abroad. The principal hypothesis of this study is that Holocaust instruction in Israel and abroad has the potential to bring about a moral change, and the question is, what is the desired moral change and how is this to be accomplished?

The didactic models at schools in Israel and abroad maintain, to varying degrees, formal curricula that impart historical and literary knowledge, alongside informal curricula that constitute a scholastic

\section{Introduction}


platform ranging around a central theme. This theme can range around a broad axis of possibilities, placing an emphasis on various aspects of the events: behavioral-cognitive, emotional, and moral. The various emphases can contribute differently to the shaping and structuring of national-Jewish values on the one hand, and universal values on the other, in the study of the Holocaust.

Each of these moral emphases has its own justifications. From a national perspective, the Holocaust was, first and foremost, the Holocaust of the Jews of Europe, where every Jew was a target of extermination. In the words of Rabbi Lau: "Not all the victims were Jews, but all the Jews were victims."

However, from a universal perspective, the Jews were not the only ones who were murdered: Gypsies, the disabled, Negroes, homosexuals, and opponents of the Nazis constituted approximately $50 \%$ of all the victims of the mass murder that took place in Poland. This fact turns the events of World War II into events that are not merely the outcome of racism with a religious background, but also an expression of dehumanization and intolerance of people who are different per se - either those who practice a different religion or those with physical, sexual, or cultural differences.

Holocaust instruction and remembrance in the Jewish and non-Jewish world is of major importance, since the very occurrence of these events in the enlightened western world is a testimonium paupertatis and a mark of disgrace for the modern world, which allowed this to take place, and with the initiator and perpetrator of these crimes against humanity being one of the most important and cultured countries in Europe itself. Teachers, educators, guides, and policymakers can choose where to focus the spotlight in all matters related to the lessons to be learned from these historical events: Whether to emphasize the events as a manifestation of human evil, of intolerance, of discrimination, of innate barbarism, or whether to choose to emphasize hatred of the Jews, racism and the destruction of Europe's Jewish community.

This article attempts to systematically examine the contribution of this teaching activity, including formal and informal curricula, on the formation of those selfsame national and universal values, through a comparative observation of Holocaust instruction in France versus Israel. Both countries contain two major Holocaust institutes: Yad Vashem in Israel and the Memorial de la Shoah in France. The article assesses the role of the Holocaust institutes in Holocaust instruction and its connection to the school curricula, and the different relationship between the goal, i.e. teaching the Holocaust, and the means, i.e. the journey to Poland, in the two educational systems in these countries, and closely monitors this relationship between the formal and informal programs in the curricula.

The analysis is based on in-depth interviews with policymakers and an analysis of observation sessions and documents in Israel and 
France. In the context of the study questions, the article addresses the dialogue between these two sets of values in the educational discourse and in the teaching activity in the two countries, and the degree to which the national identity benefits from experiential learning by means of the journey to Poland. The article examines whether having the adolescents encounter the Valley of the Vision, which is also the Valley of the Shadow of Death, contributes to the "three-dimensionality of the memory" (Degnen, 2005) - the connection between the individual and the group and between the present and the past (Fentress \& Wickman, 1992). It also explores whether this experience can lead to a deeper insight of the assets of morality and humanism, whether it enhances the insights of the nature and essentialness of democracy, the nature of racism (in all of its forms and including the dehumanization that it involves), and the obligation to oppose racism and accept the other.

World War II ended on August 15, 1945. Between 50 and 75 million people are estimated to have lost their lives during the six years of war. The whole world had to undergo a prolonged process of rehabilitation to recover from the greatest tragedy in the history of mankind. These years were devoted to recovery and rehabilitation of all that had been lost. At the time, the Holocaust was considered one of the many elements of the war, and did not receive the collective attention it deserved, neither in the world in general nor in Israel, where Holocaust survivors constituted a significant percentage of the population (Resnik, 2003). In effect, these were years when "official denial of the Diaspora" (Don-Yehiya, 1983; Grossman, 2005; Stauber, 2000) was instituted in Israel, Holocaust memories were deliberately repressed due to the association between the Diaspora and the Holocaust. Commemoration of one was perceived as commemoration of the other. Were that not enough, the Holocaust was perceived at the macro-level as a national catastrophe, to which a conspiracy of silence should be applied (Jablonka, 1998). Nascent Israel sought to eliminate traces of the Diaspora itself and its memory, and to institute a new way of life: Therefore, it also chose to eliminate the memory of the Holocaust.

Over the years, the living memories naturally disappeared and, along with the death of Holocaust survivors, there came the realization that the Jewish Holocaust may disappear from memory in the absence of formal steps to preserve it (Knoch, 2008). This understanding that collective memory can only be preserved actively led to the development of formal and informal curricula for Holocaust instruction.

The Ministry of Education's official Jewish history curriculum provides Israeli youth with a thorough and in-depth introduction to the subject of the Holocaust when they reach the age of 16. Up to that point, the subject of the Holocaust is mentioned in various other sub-

Holocaust instruction and remembrance in Israel 
jects, such as literature and civics, but this not sufficient to furnish students with in-depth knowledge.

When young people studying in the public education stream (there are three education streams in Israel: 1. Public, non-religious stream, 2. Religious stream, 3. Haredi autonomous stream) reach the 11th grade, they learn about World War II in general, and about the Final Solution in particular. The students learn about how the Nazis came to power and about the building of the totalitarian regime in Germany, the Nazi ideology, the events of the Holocaust and the steps that led to the establishment of the Jewish state. In the religious stream, 9th graders also study a unit on the main characteristics of the Holocaust from a specifically Jewish perspective.

Informal Holocaust instruction curricula are developed and administered mainly by institutes for Holocaust instruction in Israel. These institutes operate as schools of Holocaust instruction, offering a wide range of curricula. Each institute has its own agenda and each chooses the area that it stresses in its studies, and different moral emphases. The institutes developed independently and independently developed various curricula for structuring their moral, experiential, and cognitive approach to Holocaust instruction. In Israel, it was decided in 1989 that the informal curriculum should be expanded and should include an element of experiential learning that would take place on Polish soil - a pilgrimage trip to the actual sites of the memory.

The Pilgrimage trip to Poland

- Israel
The trip to Poland is made by 11 th and 12 th graders. It is financed by the families of the students who make the journey. The trip is part of the curriculum, but is not compulsory. Between 25\% and 33\% of all students participate. It is intended for studying history at first hand, and is considered a method of Holocaust instruction through experiential learning. This method makes use of the direct learning experience whose purpose is to help the learner acquire skills and values. Experiential learning addresses the learner's senses, emotions and cognition, thereby mobilizing his entire experience (Lev, 1998).

Experiential learning is based mainly on the behavioral-cognitive approach whereby a change at the cognitive level can be triggered through the individual's experience and then further projected on the behavioral and emotional aspects of the individual's personality (Davidovich and Kendall, 2006). In order for this type of learning to take place, it must include features of active learning, cognitive and emotional processing, authenticity of subject matter (relevance for the learner), and the means for creating connective experiences (Carver, 1996).

The curriculum for the journey to Poland is one of experiential learning activities that take place outside the school premises, with the school's teachers. It is a curriculum that makes use of informal means in order to generate learning. The journey lasts approximately eight 
intensive days, during which the students visit former Jewish communities, death camps and Polish tourist sites. The visit includes exposure to intense emotional experiences, to the horror of the Nazi regime, and to the rich culture of the Jews of Eastern Europe (Romi \& Lev, 2003). The trip curriculum comprises three parts: preparation for the pilgrimage trip, the trip itself and processing after the trip. All three parts together constitute the complete trip curriculum and are almost equally important for the realization of its goals.

Academic preparation pertains to formal study of issues related to the topics that are addressed during the trip and the sites that are visited. This is the focused study of the subject matter, with the intention of clarifying the uniqueness of the Holocaust of the Jewish people in Europe. Learning takes place in three domains: the Jews of Poland, the Holocaust and Poland. The academic learning process focuses on a number of areas: the history of the Jews in Poland up to the period of the Nazi occupation; Poland during World War II; the highlights of the Nazi ideology and how it was implemented; the Jews of Poland during the Holocaust; Righteous Gentiles; Holocaust survivors after the war; ways of commemorating and coping with the memory of the Holocaust in Israel and Poland; Polish-Jewish relations during the period after the Holocaust; an introduction to Poland today and to relations between Israel and Poland; preparation for meetings with young people in Poland.

Social-Emotional Preparation - This process takes place alongside academic preparation and includes clarifying group and individual expectations; setting rules for group behavior; involvement of professionals in the preparations; holding social-emotional discussions; involvement of Holocaust study institutes in the preparations; group assignments in preparation for the journey; setting up teams and electing functionaries from among the young people; preparing a group journey booklet; preparing the parents of the students participating in the journey.

According to the instructions in the circular issued by the director general of the Ministry of Education (2009), the trip curriculum should reflect the meta-goals outlined by the Ministry of Education. These goals include acquiring knowledge of and strengthening a sense of connection to the history of the Jewish people; gaining understanding of the need for Israeli sovereignty and reinforcing the students' commitment to its ongoing existence, as well as learning universal lessons concerning democracy, human dignity and the value of life. The Ministry of Education's first and explicit requirement is for the journey curriculum to reflect all the aforementioned goals of the trip. This is the only unequivocal requirement that the curriculum contains: All the remainder are defined as recommendations typically preceded by the phrase "it is worthwhile to visit..." (Director General's

The Journey

Curriculum 
Circular, 2005). For example, recommended contents that should be included in the journey are proposed. Below we review several such suggestions.

A visit to cities and towns - To gain knowledge and understanding of the former Jewish communities that were destroyed, visits to cities and towns such as the following are recommended: Warsaw, Kraków, Lublin, Lódz, Tykocin, Góra Kalwaria, Kazimierz Dolny, Sandomierz, Leżajsk, Lańcut, Ciche, Tarnów, Częstochowa, Wieliczka.

Death camps - A visit to the death camps is also a matter of choice, apart from Auschwitz, which is compulsory: "The site of the Auschwitz-Birkenau death camp must be included in every journey." In addition, the guides can choose to visit additional camps, such as Treblinka, Majdanek, Auschwitz-Birkenau, Plaszow, Sobibor, and Chełmno.

While visiting most of the sites is a matter of choice, holding ceremonies at selected sites is compulsory: "The journey program must include participation in ceremonies at the death camps and the recommended sites" (ibid). With regard to the educational-cultural content, evening activities are compulsory, and must include group discussions whose purpose is to help the students' process their emotional experiences and discuss issues that arise during the visit to the sites. In addition, it is recommended to also enable the participants to see a cultural performance, such as a play, movie, or concert.

For the weekend activity, the director general's circular recommends attending Sabbath eve (Friday night) prayers at the Remuh Synagogue in Krakow or at the Nozyk Synagogue in Warsaw, or Saturday morning prayers. To become familiar with contemporary Poland, the circular recommends the inclusion of meetings with Polish adolescents in various social-cultures settings: joint workshops, a joint journey, or the adoption of a community.

The program for the trip to Poland, according to Israel's educational system, is based on the compulsory components and employs several educational models of moral emphases; the elective components of the journey's program add unique features to these methodologies.

The Return from the pilgrimage trip
The director general's circular recommends holding a number of meetings with the students after their return, providing students with the opportunity to discuss their feelings and thoughts after their return home, and gain understanding of "how and to what extent the trip to Poland has affected their lives after the trip on the personal, familial, social and national levels." There are additional recommendations, such as encouraging the adolescents to share the story of the trip with those close to them; organizing a Poland Evening during which those who have returned from the trip present their impressions of the journey; preparing a trip booklet; integrating their expe- 
riences in the regular curriculum; preparing texts; adopting communities; adopting Holocaust survivors and writing a final paper. Unfortunately, very little follow-up activity is carried out in practice (Davidovich et al, 2010).

Unlike Israel, in the rest of the world and in Europe in particular, experiential learning is performed based on different models. This generally consists of a one-day visit to a single site, with most of the attention being given to advance study. Below we describe Holocaust instruction and remembrance in France.

The need for Holocaust instruction and remembrance in France entered into the French collective consciousness many years after the war ended. Few survivors returned from the camps - less than 3,000. They wanted to tell their story, but nobody wanted to listen. Associations and organizations established after the Holocaust emphasized the role of the political victims and prisoners in the war, but disregarded its Jewish aspect. Although the Adolf Eichmann trial in Jerusalem aroused public consciousness in France, and highlighted the destruction of European Jewry, a turnaround took place only in the 1970s when appearance of numerous historical publications triggered a reassessment of all matters pertaining to the responsibility of the French nation and the French administration for the persecution, deportation, and eradication of French Jewry. Many documentary films were produced in the 1980s, including Claude Lanzman's film, Shoah [Holocaust], which heightened collective consciousness. At the same time, historical writings, works of art and exhibitions increased the French public's awareness of the Holocaust.

Politicization of the Holocaust began in the 1990s, with the call to contemplate and remember the nation's crimes: "We will remember so that this will never repeat itself" became the key phrase. Historical consciousness began to take shape as the French began to explore the question of responsibility, and if, in the past, the focus was on plans for the future, it became redirected to an exploration of the errors of the past.

Commemoration of the Holocaust reached a turning point. Politics began using it in order to define a national common denominator and a common national plan, turning the Holocaust into a model that was relevant for other persecuted peoples in the twentieth century. In 1993, after a prolonged debate, Francois Mitterrand - then president of the republic - decided on an official day of commemoration against racist persecution.

Nevertheless, despite the state's official efforts, France has not yet managed to afford the Holocaust a place in history and in the collective memory of the French. In the year 2000, the French government decided on another step intended to reinforce the memory - the declaration of an annual day of Holocaust remembrance at schools. In 2005, reflecting the continuing trend of commemoration, the Me-

\section{Holocaust instruction and remembrance - in France}


morial Holocaust Institute and Museum was inaugurated in Paris. It is the largest of its kind on the continent.

At the formal curriculum level, the subject of World War II first appeared in France history textbooks 17 years after the war ended. Textbooks that discussed the war placed varying emphasis on the Holocaust, according to each author's position. Some textbooks, discussed the reasons for the war at length, and addressed the question of the Final Solution. These topics were completely absent in others, such as Fernand Braudel's important textbook (Belin, 1963) which, apart from one sentence in the chapter on the results of the war, made no mention of the Holocaust of European Jewry.

Today, following the series of changes discussed above, teaching and studying the Holocaust are a compulsory part of the curriculum at junior high schools and at high schools in particular. To fit the changing spirits of the times, the curricula have undergone many upheavals and changes, but by now they have stabilized to the point of presenting a certain degree of ostensible normalization, firmly establishing Holocaust instruction in the official curricula. The topic of the annihilation of the Jews is rooted in the official intent; history and geography elementary to high school curricula, with the aim of creating "recognition of the Holocaust within the school" (Boissy, p. 15). On the other hand, the goal of the current curricula is to give the annihilation and destruction of Europe Jewry the attention that they deserve, with due consideration to research studies, recent findings, and historical developments. This means that Holocaust instruction necessarily evokes moral issues pertaining to civics and philosophy, and demands that educators develop and fine-tune specific tools for thinking about such issues and questions (Born, 1993).

To prevent these issues from establishing themselves as "ordinary" parts of the curriculum, much of the engagement in such topics took place in informal and less established settings: university summer schools, seminars and training journeys, which have become part of the established system of the Ministry of Education. A study conducted by the INRP (Institut National de Recherche Pédagogique) found that while Holocaust instruction is becoming an established part of the curricula, efforts are invested to ensure that instruction and the pedagogical tools used are not banal or shallow: This goal is accomplished through the extensive use of informal tools.

Boissy (2007) claims that this approach manages to attract students by paving the way for many extensive projects beyond the accepted and official course of study. This approach calls for interdisciplinary projects performed jointly by students in different classes, different schools, and even different countries. Here lies its attraction for the students, since it leads to the dissolution of the narrow school frameworks and the banal curricula, and becomes a means for linking historical knowledge with philosophical, anthropological, sociological, and political knowledge, and also linking moral and civil 
questions through a study of the process that led to that selfsame absolute evil. According to Boissy, touching on the subject enables the rediscovery of the various topics that are typically limited in the school framework: This allows "unifying the various human disciplines for an educational purpose; creative thinking, with civics education constituting the key word" (ibid, p. 14). As part of this multidisciplinary approach, the French began to institute a model of the trip to Poland.

The school trip from France to Poland is under the exclusive auspices of the French Holocaust Institute - The Memorial. This organization has assumed the task of expanding the Holocaust learning experience to Polish soil, as part of the informal teaching method that aims to avoid making the memory a mundane one. The journey to Poland is based on a one-day journey model, with students visiting a single commemorative site - Auschwitz-Birkenau. The journey always takes place between November and March, in order for students to experience the freezing gray weather of the city, as it prevailed in the camp most of the time. Instruction on the camp premises lasts approximately six hours, and the remainder takes place on the buses.

Eleventh and twelfth graders go on the trips (due to an overlapping of the formal curriculum), which is an integral part of the curriculum. In the schools that choose to make the trip, the trip is intended for everyone, but participation is not compulsory. Nevertheless, $90 \%$ of students choose to take part in the trip, with the remainder attending school as usual. According to the figures, the trip is made by between 2,500 and 3,000 students each year. Hence, the number of students who make the trip to Poland from France is far lower than the number of students who make the trip from Israel to Poland. The entire trip is financed by the Paris Fondation de la Shoah organization and the French Ministry of Education, which makes economic considerations regarding the journey irrelevant.

In the initial years of the project, emphasis was placed mainly on the visit itself, but experience showed that without suitable preparation, considerable time must be devoted to disciplinary problems and to establishing the significance of the site. In addition, for many years the journeys were criticized on the grounds that they are unnecessary and do not contribute to the adolescents. In 2004, the Memorial decided on a methodological change in all matters pertaining to the journey to Poland, and shifted the center of gravity from the trip itself to the preparations for the trip, and an emphasis on historical work and developing students' motivation.

Preparation for the trip takes place in the framework of the Memorial Institute, with students from all over France coming to the museum, where they visit an exhibition, take part in conversations and discussions with the pedagogical staff, participate in workshops and visit the Drancy camp near Paris. The visit to the Memorial is

The trip to from France to Poland 
compulsory, and is also subsidized for all students. In addition to the study day at the Memorial, students must spend a number of hours studying the history of the subject before going on the journey. In cases where the school is unable to visit the Memorial, the Institute sends pedagogical representatives to the school.

As part of the preparation for the trip and during the journey as well, emphasis is on historical facts, and the overall crimes of the Reich are addressed. Both the singularity of the Holocaust as a holocaust of the Jews of Europe, and its universal aspects are addressed. The declared goals of the journey are to teach the Holocaust as representative of the mindset of a modern, bureaucratic, industrial society that harnessed modernity in service of mass murder. On the day of the journey, an attempt is made to discuss all the material that was covered throughout the year.

The guide and the person bearing witness are essential in realizing this mission. The content of the trip itself is determined by the French Ministry of Education. Universality is presented in that this is annihilation that is the result of racism and anti-Semitism. Mankind per se is the topic. The Memorial has declared that its agenda does not include dealing with values but rather presenting the facts and leaving the rest to students' discretion. As a result, the emphasis is mainly on the historical aspects of the events, and the goal is to eradicate students' ignorance. After the journey, follow-up work is performed by the school teachers, who are given the task of reinforcing the knowledge through written texts, oral presentations, or visual images.

It is claimed that a one-day journey misses the mark, to some extent, since it is a "violent" journey: "The students get up early, leave beautiful Paris, find themselves in the cold in Auschwitz for a few hours, and then return to their beautiful and tranquil environment," (Dominique Trimbur, representative of the Fondation de la Shoa). The Memorial refutes these claims, explaining that the journey is merely the climax of an extended learning process, and the effectiveness of this process is what determines the significance of the journey.

The pilgrimage trip to Poland and Holocaust instruction: Israel and France
A comprehensive evaluation study conducted in Israel (Davidovich et al., 2010) found that the trips to Poland can be classified according to various methodical models. A methodical model of a trip reflects the basic form and content that the journey assumes. The trip may take place in diverse settings, each setting has its own educational and moral objectives and, therefore, each setting has a unique model for implementation of experiential learning. The models differ in their form ("how") and in their content ("content"), since they reflect specific goals. At the "how" level, one can point to differences in the organizational models of the journey in France and Israel, which differ from one another in organizational deployment, in the number of participating students, the time framework, the route, and the funding. Figure 1 depicts the differences. 


\begin{tabular}{ll}
\hline Israel & France \\
\hline $\begin{array}{l}\text { State and independent delegations } \\
\text { Students pay } \$ 1,200 \text { for the trip }\end{array}$ & $\begin{array}{l}\text { Independent delegations } \\
\text { Token fee - trips are funded by the Ministry of } \\
\text { Education and the Fondation de la Shoah }\end{array}$ \\
Eight-day trip & $\begin{array}{l}\text { One-day journey } \\
\text { All schools have the option of participating in the trips }\end{array}$ \\
$80 \%$ of schools participate in the journeys & $\begin{array}{l}90 \% \text { of students in the participating schools go on } \\
\text { the trips }\end{array}$ \\
$25 \%$ of all students go on the journey & The trips are operated by the Memorial de la Shoah \\
The trips are operated by private organizations & Visit to Auschwitz-Birkenau only \\
Visit to a wide variety of sites: death camps, ghettos, & \\
Jewish cemeteries &
\end{tabular}

* Note: In France - potentially, anyone can participate in the trip, but it is a matter of personal choice since participation is not compulsory. School participation depends on approval of the pedagogical project submitted to the Memorial or to the Fondation. The trips are also operated by the Fondation. This study is based on data on trips organized by the Memorial, which operates the majority of the journeys.

The different organizational models are also a manifestation of different worldviews at the programmatic level. In Israel, considerable importance is attached to the moral and emotional aspect of the journey, while in France a deliberate attempt is made to avoid these issues by focusing on purely historical facts. In Israel, Zionist and Jewish topics are the dominant contents of instruction, while the universal aspect is of secondary importance (Davidovich et al, 2010). In contrast, in France the universal values are paramount, with the uniqueness of the Holocaust being downplayed (see study by the French Foundation for the Commemoration of the Holocaust, 2005).

One can learn about the importance and sanctification of universality from the recently publicized affair entitled Dreyfus 2010. Catherine Pederzoli, a Jewish history teacher at a school in the city of Nancy, France, was suspended on charges of breaching the principle of secularism ("laicity"). The school superintendents from the Ministry of Education who wrote the report against Pederzoli noted that the teacher used the word "Shoah" many times when talking to them, but used the word term "genocide," which is more "neutral and legal," only twice. The superintendents reached the conclusion that, through her behavior, Pederzoli had breached "her commitment to neutrality and to the secular principle," i.e. the principle of separation of church and state. The superintendents further claimed that the teacher invested too much time in organizing trips for the study of Jewish history in Central Europe; they were concerned that such efforts would be at the expense of other parts of the curriculum (Haaretz, 2010).

A comparison of the content-related aspects in the two countries shows that the organizational model is, to a great extent, the result
Figure 1:

Organizational Model of the Journey: France - Israel 
of integral content-related aspects of the journey and Holocaust instruction as a whole (Figure 2).

Israel

Formal instruction: teaching the Holocaust in eleventh and twelfth grade history classes

Informal instruction: $80 \%$ of students visit the Holocaust institutes

Preparation only for those going on the trip

There is no follow-up after students return from the journey

Intensifying the emotions with ceremonies and group discussions in the evenings

Emphasizing Zionist and Jewish values by presenting the culture of the communities that were destroyed, visits to cemeteries, bearing the national flags and reading prayers at the memorial sites

\section{France}

Formal instruction: teaching the Holocaust in eleventh and twelfth grade history classes; teaching in a multidisciplinary setting

Informal instruction: a visit to the Holocaust institutes is compulsory for all students

All student prepare for the trip

Further processing with the teachers after the journey

Refraining from dealing with emotions

Refraining from dealing with values by emphasizing the historical facts
Figure 2:

Comparison

Holocaust curricula: France - Israel
A comparison of the content-related and organizational model of the experiential curricula in Israel and France underlines the substantive differences that separate these two educational systems' although both make use of experiential learning to promote a broader agenda that is outlined by policymakers. It is clear that the different curricula attach different importance to the trip. In Israel, the journey is long, complex and intensive, and includes a tight and busy schedule of sites and assignments. The length and depth of the trips are indicative of the scope of expectations from this learning experience. In contrast, in France the trip is brief, and is perceived as the climax of a prolonged learning process.

Each of the models has its advantages and disadvantages. The extended model allows students to process the experience, and exposes them to the various and diverse aspects of the annihilation. Within a longer timeframe and through visits to a large number of sites, students gain several perspectives, and are exposed to both the universal and the particular implications of the Holocaust. The disadvantages of the model are its financial costs, as well as its logistical demands, as a result of which participation is relatively limited.

The concise model, in contrast, when accompanied by intensive preparation, presents a symbol of the Holocaust, and no more. Within this model, the learning experience is directed to a single place which is largely similar to other death camps. Due to its rigid structure, the concise model allows all students to make the journey as a single group, requiring little bureaucracy and limited resources. Contrary to the traditional perception that a longer stay in the site of 
learning is more effective, studies show that the foundation rather than the length of the journey is the decisive factor that determines effectiveness of the learning process (Davidovich et al, 2010). Hence eight days are not necessarily more effective than one day: The difference lies in the intensity and depth of learning that takes place before and after the journey. This approach does not sit well with the practical method adopted by schools in Israel, which attributes great significance to the journey's transformative effect and its role as a generator of change.

The trips to Poland, from the outset, have been the subject of stormy disputes in both Israel and France. In Israel, supporters of the trips claim that the journey has many advantages: it provides students' with tools to cope with the emotional and cognitive aspects of the Holocaust; strengthens students' identification with the State of Israel, with its democratic identity, and strengthens their sensitivity to human rights; strengthens their sense of national heritage and universal values; strengthens their understanding of the importance of an independent Jewish state, and provides students with an opportunity "to touch" the Holocaust.

On the other hand, the opponents claim that the pilgrimage trip has disadvantages in various areas. From a social standpoint, inequalities are created by the high cost of the journey $(\$ 1,200$ per participant), which means that participation is not universal, and delegations comprise students from a specific socioeconomic stratum. It has also been claimed that the trip has become a type of warped pilgrimage that includes bizarre worship of kitsch and death. The trip, which is designed to be educational, is becoming a team-building experience, a sort of youth road trip which is inconsistent with the official goals of the journey. In addition, the emphasis in the trips is placed on destruction, with very little attention being paid to the tremendous wealth of life, culture and activities that took place in the thousand years of Eastern European Jewry's existence. Critics of the trips also make claims against its declared goals, on the grounds that these are tainted with a nationalist-religious political agenda that preaches isolation and xenophobia, and neglects the humanist-universal aspects of the lessons to be learned from the Holocaust.

In France, too, there is a dispute on the need for the one-day journey to the scenes of the Holocaust. The supporters claim that the trip brings the students closer to the values which they wish to impart to their students, allows students to put things in perspective, and gives them a sense of the killing that took place. The opponents, on the other hand, claim that there is too much preoccupation with the Holocaust, and the journeys are exploited as a means of propaganda that does not promote the interests of the French nation.

The two models together teach us about the inseparable connection between the goals and the means. The French model represents a direct continuation of the concrete approach to teaching the 
Holocaust. The trip, a direct continuation of the curriculum, is essentially a cognitive journey. Although emotional and moral aspects definitely exist, they are not elaborated upon. This is a businesslike and brief model that maintains the proportions in all matters related to expectations from the trip. These proportions are also manifested in its length, i.e. a short visit that constitutes the continuation of a clear cognitive state of mind. The entire trip is operated by an institute that teaches about the Holocaust, and thus the compatibility and continuity between the goals and the means is retained.

The Israeli model is indicative of the scope of the weight and expectations attributed to this experiential learning. It is a complex bureaucratic operation, due to requirements of organizing an extended journey for many students. The contents, organization, preparation, and registration are all the responsibility of the schools. Holocaust institutions play no part in operating the trips, which are controlled by private companies. At times, this is liable to complicate the project even more. Unlike France, the Israeli model tries to "cover all bases," and impact students' cognition, emotions, and values. Students' feel overloaded as result of these ambitious aims and the pretentious view of the actual visit to the memorial sites as a change factor, attaching less weight to the processes that accompany such transformation. This is the specific mindset that is manifested in the Israeli education system, where it seems as if quantity is equal to quality. Attempts to introduce a shortened model proved unsuccessful, due to financial considerations and lack of consensus (Golan, 2005).

Discussion and Summary
In the present framework an attempt was made to compare Holocaust instruction in Israel and in France. The comparison between the formal and informal curricula in both countries shows that both systems share this study's basic assumption concerning the inherent potential of teaching the Holocaust to the younger generation. Nevertheless, each country has a clear goal toward which it directs its students. The State of Israel, the Jewish state, perceives the Holocaust mainly through nationalist and Zionist eyes, directing the younger generation to learn particular lessons. This tendency can be identified from the structure and from the contents of the curricula which, jointly, are indicative of the role played by national values and emotion in Holocaust instruction. The formal curricula accounts for a small proportion of the overall curriculum, and most expectations focus on the trip, which is structured as a sequence of powerful emotional and moral experiences that are intensified by ceremonies, flags, singing, prayers and an emphasis on identification with the national and religious attributes of the victims. The intensity of the Israeli model lies in exposing the younger generation to its people's past, and in the inherent advantages of experiential learning. Nevertheless, its weaknesses include the limited connection between the formal curricula and the trip; an incompatibility between the institutions that teach about the 
Holocaust in Israel and the organizations responsible for guiding the students in Poland; and the exclusion of entire populations for economic reasons. Excessive emphasis on nationalism and Jewishness, as well as excessive hopes from the journey, have become the center of gravity of the learning process.

The French model, in contrast, represents a shortened version that is operated from start to finish by the Institute for Holocaust Studies. The formal curriculum is compatible with the journey program and includes all the students in each grade. Considerable attention is devoted to the universal lessons of the Holocaust. The process is based on complete cooperation between the school, which is in charge of the content, and the Institute for Holocaust Studies, which is in charge of the informal aspects. However, this model tends to exclude essential Jewish aspects of the Holocaust, creating a tremendous injustice to history.

Hence one can sum up and say that the Holocaust curriculum in France is very different from the one in Israel. This is manifested in both the formal and the informal curricula. One can see that the curriculum was created in an attempt to objectively report the historical facts, without guiding students to specific feelings or conclusions. Nevertheless, the overall approach of historical reporting, while relying on cognition alone, also involves the advancement of a certain agenda - the universal agenda. The formal and informal curricula are well integrated, due to the compatibility and congruence between the didactic content and the experiential content. The concise trip is compatible with the overall approach of Holocaust instruction that prioritizes the cognitive aspects of the learning experience, as the principal aspect. The trip offers an opportunity to view the subject matter at close hand, but does not constitute the main aspect of the teaching process. This is reflected in the time invested in the activities that preceded and follow the journey. Most of the efforts are devoted to establishing students' factual and historical knowledge before they see things at first hand. In this manner, the students come to see things from a historical perspective, with an orientation towards the universal aspects, and with no special emphasis on the Jewish or singular aspects of the Holocaust.

It is evident from the findings that the trips to Poland offer hope for the Jewish people and the world. The very fact that they are held indicates the educational system's need for them, as well as the level of expectations from them. Each country has different hopes from these trips; Israel hopes that Poland will return students to the folds of Judaism, Zionism and Israeliness. France hopes that Poland will return and reinforce humanism, equality, the value of life, and the value of man.

Both systems would benefit by adopting some of the elements of the other. Israel should teach its students the universal aspects of the Holocaust, in order to bring the world closer to it. At the same time, 
the world should place greater emphasis on the unique aspects of the Holocaust, lest it forget that an entire community was meant to be erased from the world purely because of its "race". The dialogue between schools in Israel and France should be expanded, and the idea of creating joint curricula should be considered, in order to expand the perspective of each country vis-à-vis the worldview that recognizes universality but, at the same time, does not disregard the universal connection.

\section{References}

Carver, R. "Theory for practice: A framework for thinking about experiential education." The Journal of Experiential Education, 19, 1996. 8-13.

Davidovich, N., and Kendall, Y. "Joint Trips by Israelis and Germans - Beyond the Experiential Upheaval." Kivunim Hadashim, 14, 2006. 152-164.

Degnen, C. "Relationality, place, and absence: A three-dimensional perspective on social memory." The Sociological Review, 53, 2005. 729-744.

Don Yehiya, E., and Lieberman, Y. "The Dilemma of Culture in the Modern State: Changes and Developments in Civil Religion in Israel." Megamot, 28(4), 1984. 461-485.

Fentress, J., and Wickham, C. Social memory. Oxford: Blackwell, 1992.

Golan, Y. To Poland and back in 24 hours. www.zazu.co.il/Article.asp?artId=641 (2005)

Graetz, Z. Chronicles of Israel. Volume 4. Tel Aviv: Jezreel, 1954.

Grossman, H. "The March of the Living." Kesher Ayin, 147, 2005. 12-14.

Handel, M. (1950). Gzerot Tach Vetat [the Chmelnitsky Massacres of 16481648]. Jerusalem: Kiryat Sefer.

Jablonka, H. (1998). Holocaust survivors in Israel - first summaries. Bshvil Hazikaron, 26. Jerusalem: Yad Vashem, The Central School for Holocaust Studies.

"Jewish teacher in France suspended for teaching 'too much' about the Holocaust." Haaretz, 1/9, 2010.

Knoch, H. "The search for authenticity: Memory, emotions and testimony in today's Germany." Tabur, 1, 2008. 10-23.

Lev, M. The effect of youth journeys to Poland on their positions vis-à-vis the Holocaust in the cognitive domain and in the emotional domain. Master's thesis. Bar Ilan University, Ramat Gan, 1998.

Resnik, J. "Sites of memory of the Holocaust: Shaping National Memory of the Education System in Israel." Nations and Nationalism, 9, 2003. 297-317.

Romi, S., and Lev, M. "Israeli adolescents' knowledge, emotions and positions vis-à-vis the Holocaust." Megamot, 42, 2003. 219-239.

Stauber, R. The lesson for the generation - Holocaust and heroism in the minds of the public during the 1950s. Jerusalem: Ben Zvi Institute, 2000.

The Ministry of Education and Culture. Youth journeys to Poland - "It is my brothers that I seek," Director General's Circular, 2009.

\section{Interviews, Documents and Observation}

Interview with Fondation de la Shoa-Paris representative Dominique Trimbur, February (2009).

Interview with the director of the Memorial, Jacques Fredj, February (2009).

Interview with Olivier Lalieu, who is in charge of school journeys by students to Poland at Memorial de la Shoah, February (2009). 
Interview with Charlotte Le Provost, who is in charge of pedagogical programs at Memorial de la Shoah, February (2009).

Interview with Alexandre Doulout, guide and escort from Memorial de la Shoah, February (2009).

Telephone interview with Alban Perrin, supervisor at Memorial de la Shoah in charge of pedagogical work at schools, February (2009).

Interview with Ariel Sion, director of the library at Memorial de la Shoah, February (2009).

Interview with Henri Nadroast, representative of the French Ministry of Education, February (2009).

Interview with a rectorat $[s i c]$ representative from the French Ministry of Education, February (2009).

Interview with a history and philosophy teacher from Cezanne School, on a flight to Poland, February (2009).

Interview with a teacher returning from the journey, February (2009).

Interview with a teacher from a vocational school, February (2009).

Short interview with students from Cezanne School, February (2009).

Observation of a French shareholder's journey to Poland, February (2009).

\section{Documents}

Document 1 - Call on schools to participate in the project.

Document 2 - 2008-2009 registration form - pedagogical project.

Document 3 - Itinerary of school journey to Auschwitz.

Document 4 - Student registration form.

Document 5 - Teacher's commitment declaration document.

Document 6 - Pre-journey teacher's manual.

Document 7 - Student's manual.

Document 8 - taken from the Memorial's information sheets (brochure); pedagogical activity for elementary school, junior high and high school students, and training workshops for college students and teachers, 2008-2009.

Document 9 - Information sheet from the Fondation de la Shoa, Memorial's partner and subsidizer, on how to teach the subject of the Holocaust.

Document 10 - Hebrew information sheet presenting the Memorial.

"Le monde actuel, histoire et civilisation", Belin, Paris, 1963.

Jean Francois Boissy, Shoah a l'age democratique quelle enjeux? ed Armand Colin, Paris, 2007.

Dominique Born, Cahiers de la Shoah, no 1, 1993.

\section{Websites}

Yad Vashem: http://www.yadvashem.org/hp_he.htm

The Memorial de la Shoah in France: http://www.izieu.alma.fr/anglais/ frame_principale.htm 